\title{
INTEGRAL INEQUALITIES OF KANTOROVICH AND FIEDLER TYPES FOR HADAMARD PRODUCTS OF OPERATORS
}

\section{PATTRAWUT CHANSANGIAM}

Abstract. The scalar Kantorovich inequality is a reverse weighted arithmetic-harmonic mean inequality. In matrix case, this inequality is also a reverse version of Fiedler's inequality. In this paper, we establish several Kantorovich and Fiedler types integral inequalities involving Hadamard products of continuous fields of Hilbert space operators. Kantorovich type inequality in which the product is replaced by an operator mean is also investigated. Such inequalities include discrete inequalities as special cases. Moreover, we obtain the monotonicity of certain maps involving Hadamard products of operators. As special cases, we get some operator versions of Fiedler matrix inequality.

Mathematics subject classification (2010): Primary: 26D15, 47A63; Secondary: 46G10, 47A64, 47A80.

Keywords and phrases: Kantorovich inequality, Bochner integral, continuous field of operators, Hadamard product, operator mean.

\section{REFERENCES}

[1] T. Ando, Concavity of certain maps on positive definite matrices and applications to Hadamard products, Linear Algebra Appl., 26, (1979), 203-241.

[2] D. ANDRICA AND C. BADEA, Grüss inequality for positive linear functionals, Period. Math. Hungar., 19, (1988), 155-167.

[3] Y. M. ARLINSKII Theory of operator means, Ukrainian Math. J., 42, 6 (1990), 723-730.

[4] J. K. Baksalary and S. Puntanen, Generalized matrix versions of the Cauchy-Schwarz and Kantorovich inequalities, Aequationes Math., 41, (1991), 103-110.

[5] R. Bhatia, Matrix Analysis, Springer-Verlag, New York, (1996).

[6] S. S. DRAGOMIR, New inequalities of the Kantorovich type for bounded linear operators in Hilbert spaces, Linear Algebra Appl., 428, (2008), 2750-2760.

[7] M. FIEDLER Uber eine ungleichung fur positiv definite matrizen, Math. Nachrichten, 23, (1961), $197-$ 199.

[8] J. I. FuJII, The Marcus-Khan theorem for Hilbert space operators, Math. Japon., 41, (1995), 531-535.

[9] T. FURUTA, Operator inequalities associated with Hölder-McCarthy and Kantorovich inequalities, J. Inequal. Appl., 2, (1998), 137-148.

[10] W. GReub AND W. Rheinboldt, On a generalization of an inequality of L. V. Kantorovich, Proc. Amer. Math. Soc., 10, (1959), 407-415.

[11] F. HIAI, Matrix analysis: matrix monotone functions, matrix means, and majorizations, Interdiscip. Inform. Sci., 16, (2010), 139-248.

[12] F. Hiai AND D. Petz, Introduction to Matrix Analysis and Applications, Springer, New Delhi, 2014.

[13] K. V. Kantorovic, Functional analysis and applied mathematics, Uspehi Mat. Nauk (N.S.), 3, (1948), 89-185. (in Russian)

[14] F. Kubo And T. Ando, Means of positive linear operators, Math. Ann., 246, (1980), 205-224.

[15] S. LiU And H. Neudecker Several matrix Kantorovich-type inequalities, J. Math. Anal. Appl., 197, (1996), 23-26.

[16] A. W. Marshall And I. Olkin, Matrix versions of the Cauchy and Kantorovich inequalities, Aequationes Math., 40, (1990), 89-93. 
[17] J. S. Mathru And J. S. Aujla Hadamard product versions of the Chebyshev and Kantorovich inequalities, J. Ineq. Pure Applied Math, 10, (2009), Article 51.

[18] J. MiĆIĆ AND J. PEČARIĆ, Generalization of the Kantorovich type operator inequalities via Grand Furuta inequality, Math. Inequal. Appl., 9, 3 (2006), 495-510.

[19] M. S. MosLeHIAn Recent developments of the operator Kantorovich inequality, Expositiones Mathematicae, 30, (2012), 376-388.

[20] R. Nakamoto And M. Nakamura, Operator mean and Kantorovich inequality, Math. Japon., 44, (1996), 495-498.

[21] P. G. Spain, Operator versions of the Kantorovich inequality, Proc. Amer. Math. Soc., 124, (1996), 2813-2819.

[22] T. YAMAZAKI, An extension of Kantorovich inequality to $n$-operators via the geometric mean by Ando-Li-Mathias, Linear Algebra Appl., 416, (2006), 688-695.

[23] F. Zhang, Equivalence of the Wielandt inequality and the Kantorovich inequality, Linear Multilinear Algebra, 48, (2001), 275-279. 